\begin{abstract}
The Natural Barriers Thrust supports scientific studies of the natural system at the proposed repository site of Yucca Mountain. It stresses the realistic representation of the natural system with respect to processes and parameters, by means of laboratory, field, and modeling studies. It has the objectives to demonstrate that the natural barriers can make large contributions to repository performance, supporting the multiple-barrier concept for geological disposal of high-level radioactive waste; and to reduce the overall cost of repository development by elimination of unnecessary engineered components, given the demonstrated natural barriers performance. In this overview we enumerate the research projects within the Natural Barriers Thrust grouped under five elements: (1) Drift Seepage, (2) In-drift Environment, (3) Drift Shadow, (4) Unsaturated Zone Flow and Transport, and (5) Saturated Zone Flow and Transport. The long-term strategic plan of the Natural Barriers Thrust and some key results are also briefly described.
\end{abstract}




\section{Office of Science and Technology and International, Natural Barriers Thrust Overview}

Bo Bodvarsson and Yvonne Tsang

Earth Sciences Division

Lawrence Berkeley National Laboratory, Berkeley, CA

\section{Introduction}

For the Office of Science and Technology and International (OST\&I), Office of Civilian Radioactive Waste Management, United States Department of Energy, the Natural Barriers Thrust supports scientific studies of the natural system at the proposed repository site of Yucca Mountain. OST\&I has the mission to provide advanced science and technology to continually enhance our understanding of the repository system and to reduce cost and schedule for the OCRWM mission without sacrificing safety. The science and technology effort in the OST\&I complements the proposed repository design, performance assessment, and other baseline engineering and scientific studies conducted by the OCRWM's Office of Repository Development (ORD) at the Yucca Mountain site. OST\&I presently supports five major research programs (or "thrusts"):

- Source Term

- Material Performance

- Radionuclide Getters

- Natural Barriers

- Advanced Technology

Summary of projects supported by the five thrusts can be found in the OST\&I annual report [1]. The Natural Barriers Thrust stresses the realistic representation of the natural system with respect to processes and parameters, by means of laboratory, field, and modeling studies. This natural system is composed of the unsaturated and saturated zones at the Yucca Mountain site, and the hydrothermal-chemical environment within waste emplacement drifts. It complements more specific areas of research covered by the other Science Thrusts (Figure 1): the Source Term Thrust, which focuses on waste forms, and on the speciation and solubility of radionuclides; the Material Performance Thrust, which emphasizes issues pertaining to corrosion of drip shields and waste packages, and the Radionuclide Getters Thrust, which aims at trapping and retardation of radionuclides within the waste package and emplacement drifts. 


\section{OST\&I Science Targeted Thrust Areas}

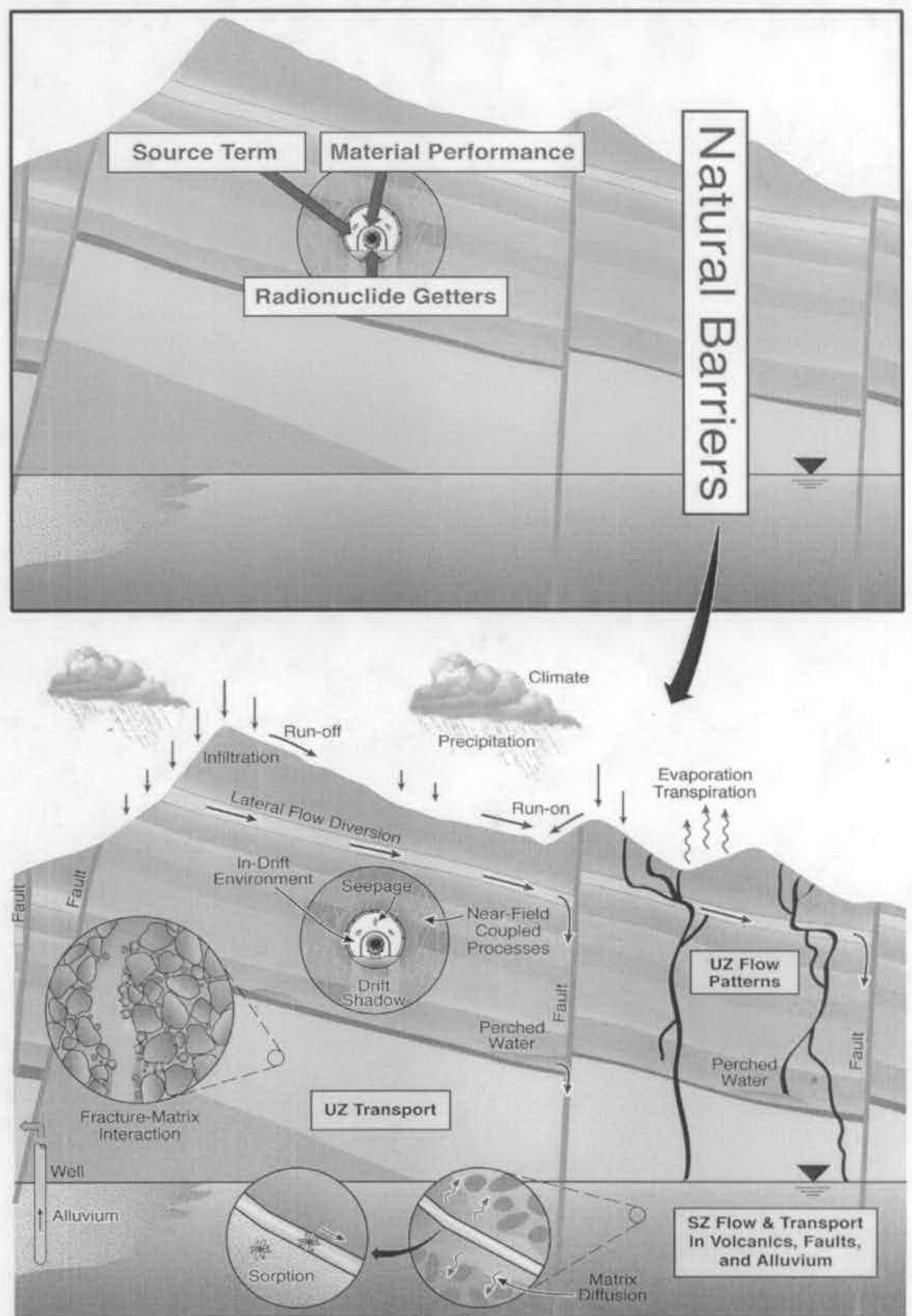

Figure 1 OST\&I Science Thrust Areas 
During the last 15 to 20 years, a substantial amount of research has been devoted to Yucca Mountain by the ORD. Site characterization of Yucca Mountain has been successfully carried out through experiments in tens-of deep (reaching the water table) surface-based boreholes and in an underground facility. Extensive computation models have also been developed to simulate and understand the relevant processes at the site. However, in spite of the quantity of data collected and the knowledge acquired, the complexity of processes in the fractured rock, as well as the scarcity of studies in the unsaturated zone fractured rock in general prior to the recent research on Yucca Mountain, make it necessary for the project to adopt significant conservatism in the Total System Performance Assessment (TSPA). This conservatism has been noted by many review committees. In an International Peer Review of the Yucca Mountain Project TSPA for Site Recommendation, the Nuclear Energy Agency (NEA) of the Organization for Economic Cooperation and Development (OECD), and the International Atomic Energy Agency (IAEA), wrote that [2]:

...demonstrating understanding should be complementary to demonstrating compliance and of at least equal importance. Two approaches are needed. The first is to present what is considered to be a realistic (i.e., nonconservative) analysis of the likely performance of the repository using realistic assumptions and data....The second approach is an analysis for compliance purposes where conservative assumptions and parameter values are used to make the case more defensible.

More recently, NEA wrote [3] regarding a TSPA analysis related to showing compliance:

Due to the use of pessimistic parameter values and conservative assumptions, the performance of the repository is likely to be more favourable than that indicated by the analyses. Conservatism of the analyses constitutes an additional qualitative argument for safety, although conservatism in and of itself may also be interpreted as a lack of knowledge, and may thus detract from confidence. Conservatism is inevitable, and greatly to be preferred to optimism, but should be used and managed judiciously.

The Natural Barriers Thrust recognizes that conservatism may be interpreted as a lack of knowledge, and aims to reduce conservatism through increasing knowledge. We believe that if certain key conservatisms can be successfully addressed, it may be that it can then be shown that Yucca Mountain provides sufficient public health protection-even in the unlikely event that engineered systems have lost their integrity earlier than expected. The proposed 2005 Environmental Protection Agency (EPA) two-tier standard beyond the original period of 10,000 years emphasizes the significance of the natural system's contribution to repository performance over geological time scales. Human civilization with recorded history has existed for approximately 10,000 years. On the other hand, geologic records over tens of thousands to millions of years are well established for natural attributes.

The Natural Barriers Thrust has the following objectives: 
1. To demonstrate that the natural barriers can make large contributions to repository performance, supporting the multiple-barrier concept for geological disposal of high-level radioactive waste.

2. To strengthen the natural barriers analysis for periods up to and beyond the expected occurrence of peak dose, when the extrapolation of engineered performance may not be relied upon.

3. To reduce the overall cost of repository development by elimination of unnecessary engineered components, given the demonstrated natural barriers performance.

\section{Specific Purpose and Focus}

The purpose of the Natural Barriers Thrust is to investigate various important aspects of the natural barriers; to demonstrate their significance to the performance of the repository; and to provide data, process understanding, and new models to enhance the defensibility of the license application. The TSPA represents the entire natural system in a conservative manner, thus emphasizing a reliance on the engineered barrier system. However, the success of the proposed Yucca Mountain repository hinges on the very significant performance of each of the multiple barriers (natural and engineered).

The natural barriers will have to play a key role in reducing long-term concentration of radionuclides that may enter the accessible environment. Findings to date have indicated that the natural barriers at Yucca Mountain have the potential to retard or mitigate transport.

The focus for natural barriers studies is on:

- $\quad$ Peak Dose Evaluation: Realistically accounting for the probability of water contacting waste packages and waste may significantly reduce the calculated peak dose. - Radionuclide Transport Evaluation: Realistically accounting for enhanced matrix diffusion and sorption to retard and disperse the radionuclides, breakthrough at the compliance boundary may be significantly delayed, allowing radioactive decay to reduce dose.

- Uncertainty Reduction: With realistic representation, uncertainties can be constrained, and conservative assumptions can be replaced with more reasonable and defensible scenarios and calculations, leading to a reduction in the calculated peak dose. - Process Understanding: With a unified thermal, hydrological, and chemical model that addresses key issues from three thrust areas-Source Term, Materials Performance, and Natural Barriers-investigators can more accurately determine the potential extent of waste package corrosion, waste dissolution, and in-drift radionuclide transport, which controls radionuclide release into the near-field rock formation.

- $\quad$ Significant Cost Reduction: With increased reliance on a more realistic representation of the natural barriers, costly engineered components may be eliminated. 


\section{Basic Elements of the Natural Barriers Thrust}

From the repository drifts to the accessible environment, the basic elements of the Natural Barriers Thrust are:

1. Drift Seepage

2. In-drift Environment

3. Drift Shadow

4. Unsaturated Zone (UZ) Flow and Transport

5. Saturated Zone (SZ) Flow and Transport.

As illustrated in Figure 1, the natural system components are interrelated and coupled to waste form and waste packages within the drifts, encompassing the unsaturated zone (UZ), through the saturated zone (SZ), to the compliance boundary.

\section{Drift Seepage}

Representation of drift seepage and the amount and chemistry of water contacting waste packages and waste in the TSPA is believed to be conservative. The Natural Barriers Thrust is investigating various ways of obtaining an improved understanding of the seepage process under different repository conditions. This effort includes enhanced data collection to reduce uncertainty, investigation of coupled processes during the thermal period, and investigation of the role of natural ventilation to greatly reduce or eliminate seepage.

- Suppression of seepage by natural ventilation. Ventilation and heat-induced circulation, caused by air-density variations resulting from temperature differences within drifts, can lead to evaporation and removal of moisture, preventing it from contacting waste packages. It is likely that these processes prevent drip formation and thus seepage into the drifts, thus alleviating the need for costly in-drift engineered components. - $\quad$ Self-sealing due to chemical precipitation around the drift. This results from coupled thermal, hydrological, chemical, and mechanical processes; it could change the flow pattern around the drift and potentially greatly reduce seepage into drifts.

The OST\&I Natural Barriers funded projects related to drift seepage are:

- $\quad$ "Coupled In-Drift, Near-Field, and Mountain-Scale Fluid and Heat Flow Processes" (FY2005 start-up) by G. Danko, J. T. Birkholzer, and S. Finsterle

- "Integrated Assessment of Critical Chemical and Mechanical Processes Affecting Drift Performance: Laboratory and Modeling Studies" (FY2005 start-up) by D. Elsworth, J. Rutqvist, A. S. Grader, C. J. Marone, and E. Sonnenthal

\section{In-Drift Environment}

The in-drift chemical environment plays a key role in determining the potential extent of waste package corrosion and the subsequent possibility of radionuclide release into the near-field rock. In the current Yucca Mountain Project (YMP) approach, the coupled thermal, hydrological, and chemical processes within the drift are described by several zero- or one-dimensional models, which leads to multiple accounting of water available 
for waste dissolution and thus to a conservative representation of the drift barrier function in preventing release of radionuclides to the near-field rocks. Three of the OST\&I Program thrust areas - Source Term, Materials Performance, and Natural Barriers - have a joint approach toward investigating ways to remove some of the conservatism in the current project approach (as illustrated in Figure 2), thus achieving a more realistic representation of the drift barrier performance:

- Integrated model to replace the current approach of multiple models, each describing an individual process - contributing discretely to (for example) the water composition of the end members, or salts on the waste package surfaces, or interactions with dust within the drift - which limits the YMP's ability to address key questions concerning the in-drift chemical environment. A fully coupled approach initiated in the OST\&I that rigorously accounts for mass balance will improve the representation of the drift barrier function.

- Coupling of in-drift transport with UZ processes in surrounding rocks. There is currently no integrated treatment of transport of gas, vapor, or water between the nearfield rocks and the waste emplacement drifts, nor within the drift. Capture of in-drift moisture transport along the drift into an enhanced model would enable a more realistic representation of evaporation and condensate movement.

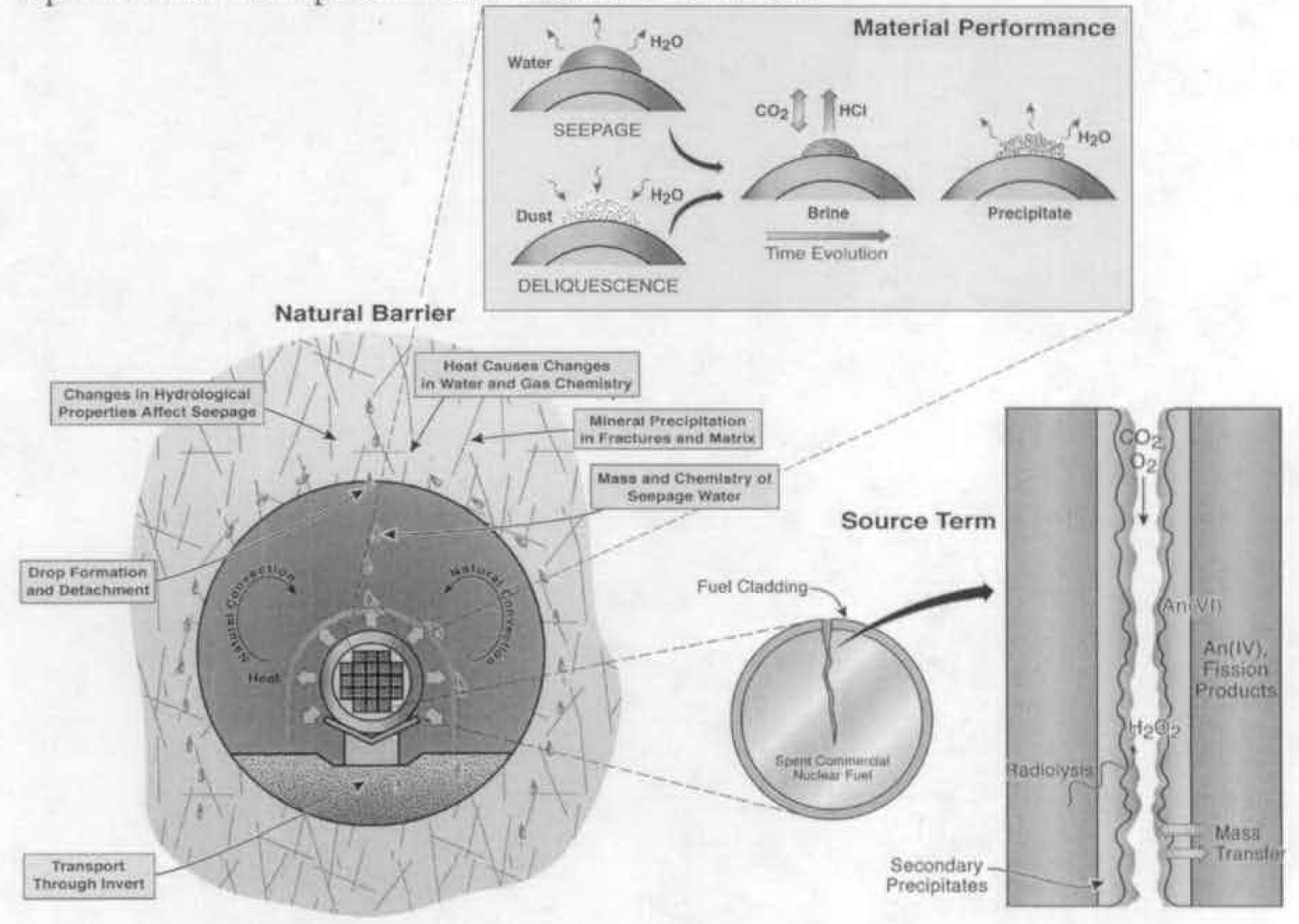

Figure 2. Integration of in-drift environment with contributions from Natural Barriers, Material Performance, and Source Term Thrust Areas 
The OST\&I funded projects related to the in-drift environment are:

- $\quad$ "An Integrated In-Drift/Near -Field Flow and Transport Model with Reactive Chemistry" (FY2005 start-up) by J. Birkholzer, E. Sonnenthal, S. Mukhopadhyay, M. Reagan, and T. Xu

- "Coupling Thermal-Hydrological-Chemical Models to Process Models on Waste Packages" (FY2005 start-up) by Spycher, G. Zhang, C. Steefel, E. Sonnenthal, and Z. Zheng, under Materials Performance Thrust

- . "A Model for Radionuclide Release from Commercial Spent Nuclear Fuel" (FY2005 start-up) by C. I. Steefel, J. Apps, N. Spycher, and E. Sonnenthal, under Source Term Thrust

\section{Drift Shadow}

The drift shadow is a region below a void in an unsaturated environment that is partially sheltered from downward-percolating water. It forms when the capillary forces are too weak to fully draw percolating water into this region. The drift shadow concept is not incorporated into the TSPA, which assumes release of radionuclides into, and fast transport through the fractures whenever seepage at the top of the drift occurs. The drift shadow, once demonstrated and validated, could greatly enhance repository performance by:

- Delaying radionuclide release by thousands or tens of thousands of years. Drift shadow is the natural consequence of water diversion around an underground opening (resulting from the negative capillary pressure in the rock), giving rise to greatly reduced water flux immediately below the opening - thus significantly limiting the mobility of radionuclides immediately below the drift.

- $\quad$ Reducing peak dose. Significantly reduced transport velocity in the shadow zone leads to delayed radionuclide breakthrough and reduced peak dose.

The OST\&I Natural Barriers funded projects related to drift shadow are:

- "Nature of Drift Shadows at Analogue Sites" by T. Kneafsey, T. Ghezzehei, G. Su, P. Dobson, and B. Marshall

- $\quad$ "Testing the Concept of Drift Shadow" by J. Paces, L. Neymark, T. Ghezzehei, E. Majer, and P. Dobson

- $\quad$ "Testing the Concept of Drift Shadow with X-ray Absorption Imaging Experiments" by S. J. Altman, C. K. Ho, A. Forsberg, and W. Peplinski

\section{Unsaturated Zone (UZ) Flow and Transport}

The UZ is the main natural-barrier component: it delays, retards, and sorbs radionuclides, and if represented realistically, can contribute to significantly to dose reduction. The TSPA representation of UZ transport is conservative. The Natural Barriers Thrust is investigating the different $\mathrm{UZ}$ retardation processes, with the aim of reducing the uncertainty and conservatism of the present model: 
- $\quad$ Effectiveness of matrix diffusion in retarding radionuclide transport

- $\quad$ Validity of the $\mathrm{K}_{\mathrm{d}}$ approach and measurements based on crushed rock samples

- $\quad$ Validation of radionuclide transport and TSPA approaches

- $\quad$ Other processes such as lateral diversion, permeability barriers below perched water bodies, and flow in faults.

The OST\&I Natural Barriers funded projects related to UZ flow and transport are:

- "Enhanced Retardation of Radionuclide Transport in Fractured Rock" by H. H. Liu, Y. Zhang, Q. Zhou, and F. J. Molz

- $\quad$ "Peña Blanca Natural Analogue" by S. S. Levy, P. F. Dobson, M. Fayek, P. Goodell, R. Ku, and M. T. Murrell

- $\quad$ "Matrix/Fracture Flow in Subrepository Units" by L. Neymark, J. Paces, D. Vaniman, and S. Chipera

- "Pore Connectivity, Episodic Flow, and Unsaturated Diffusion in Fractured Tuff" by $\mathrm{Q}$. Hu, R. P. Ewing, and L. Tomutsa

\section{Saturated Zone (SZ) Flow and Transport}

Many processes that contribute to the SZ barrier function are represented conservatively in the TSPA. Improved understanding of the SZ can improve the description of the SZ barrier function, thus removing some of the conservatism in the present project model description. The Natural Barriers Thrust addresses the following topics related to the SZ: - $\quad$ Determining if reducing conditions are pervasive in the SZ for enhanced retardation. One possible natural barrier to radionuclide migration in the SZ is the presence of nonoxidizing or reducing environments; the mobility of some radionuclides is known to greatly diminish in reducing groundwater.

- Removing conservatisms in description of the retardation mechanisms. Processes leading to retarded radionuclide transport include matrix diffusion, dilution, and sorption in the SZ.

- $\quad$ Gaining an understanding of the role of colloids in radionuclide transport.

- Investigating the dispersive nature of plumes in fractured volcanic rocks. In the current SZ models, radionuclide plumes are predicted to disperse to a small extent, and therefore have a relatively narrow shape. Such a representation of plumes limits the possibility of sorption (and thus retardation) processes to occur. The small lateral dispersion exhibited by these plumes as represented in the current models may be relatively unusual, compared to dispersion observed with chemical plumes at other sites in similar geologic settings.

The OST\&I Natural Barriers Thrust places significant focus on the SZ to explore whether orders-of-magnitude dose reduction by diffusion, dilution, sorption, and other mechanisms can be demonstrated. Funded projects related to SZ Flow and Transport are:

- "Determining the Redox Properties of Yucca Mountain-Related Groundwater, Using Trace Element Speciation for Predicting the Mobility of Nuclear Waste" (FY2005 start-up) by J. Cizdziel, V. Hodge, and K. H. Johannesson 
- $\quad$ "Field Studies for the Determination of Transport Properties of Radioactive Solutes and Colloids, Using Chemical Analogues" (FY2005 start-up) by B. Freifeld, P. Reimus, D. Hammermeister, J. Apps, and G. Moridis

- $\quad$ "Improved Characterization of Radionuclide Retardation in Volcanics and Alluvium" by P. W. Reimus, M. Ding, C. Scism, C. Sedlacek, S. Levy, and S. Chipera - "Carbon-14 Groundwater Analysis" by G. L. Patterson and J. Thomas - $\quad$ "Large-Scale Natural Gradient Tracer Test" by M. J. Umari, A. Shapiro, P. Reimus, E. Kwicklis, J. Earle, and M. Fahy - "Large-Scale Drawdown Test" by P. Reimus, R. C. Roback, E. Kwicklis, M.J. Umari, J. Earle, M. Fahy, R.L. Beauheim, R. M. Roberts. S. J. Altman, B. Arnold, S. Kuzio, C.-F. Tsang, H. H. Liu, and K. Karasaki

- $\quad$ "Integration of Data and Models for the Coupled Regional- and Site-Scale Models" by A. A. Eddebbarth, G. A. Zyvoloski, S.C. James, S. Mehl, M. C. Hill - "Saturated Zone Plumes in Volcanic Rock" (FY2005 start-up) by S. Kelkar and R. Roback

\section{Long-Term Strategy for Contributions to OCRWM OST\&I}

The OST\&I Natural Barriers five-year strategic plan has the stretch goal to establish a solid scientific basis for the natural system alone meeting the regulatory standard for repository performance.

Near-field studies - addressing seepage diversion, in-drift coupled processes, and drift shadow effects - hold great promise for substantial contributions toward reducing dose and delaying transport by at least two to four orders of magnitude. Steps taken in FY2005 to closely couple the Natural Barriers Thrust with the Materials Performance and Source Term Thrusts target the challenge of dose compliance to the new proposed EPA standard. For the far field, various studies-including the new starts in FY2005 on (1) field experiments investigating retardation mechanisms and colloidal transport, and (2) determining the pervasiveness of reducing conditions in SZ water for mitigating transport-all aim to greatly reduce uncertainties in transport predictions within the UZ and the SZ.

Beyond process understanding, realistic representation, and uncertainty reduction, the Natural Barriers Thrust's long-term strategy is also to cultivate alternative approaches that may demonstrate enhanced performance. For example, the currently used Kd approach implies that sorption is reversible. In light of the new regulatory compliance period of 1 million years, it is fitting for the OST\&I program to initiate experimental and modeling studies to investigate whether irreversible sorption is possible or even pervasive at Yucca Mountain. It is also in the long-term strategy of the Natural Barriers Thrust to investigate radionuclide precipitation in the $\mathrm{UZ}$ as the $\mathrm{pH}$ changes from 5 to 6 near the waste packages to about 9 in the UZ below the drifts. A readily feasible in situ testing program is to drill microboreholes in the Forty-Mile Wash east of Yucca Mountain to collect transport data from the water disposed from the SZ testing, and thus evaluate if our models can reproduce these observations. 
More far-reaching questions include the following: Should the natural geothermal gradient, which influences postemplacement convection (controlling water contacting waste packages and waste and therefore impacting peak dose), be integrated into the design of the repository layout? Should emplacement drifts be designed to be smaller and to have alternative configurations, in order to suppress seepage and water contacting waste? Can sealants or bacteria be introduced to the drift walls to enhance isolation? Can microsensors be developed to detect radiation leaks and corrosion onsets? Can geophysical tools be advanced to delineate $\mathrm{pH}$ changes and flow paths?

The long-term goal of the Natural Barriers Thrust is to improve our ability to predict the performance of the proposed Yucca Mountain repository. The focus on fundamental understanding of processes and realistic representation of the natural system would strengthen the defense of the license application, address the issues that concern the Nuclear Waste Technical Review Board (NWTRB), and respond to EPA's requirement of realistic modeling and improved understanding of processes.

Although the Natural Barriers Thrust has only been conducting research for less than two years, there have already been very significant results that could potentially lead to substantial improvement in demonstrated performance of the natural system. These include:

- Integration of Natural Barriers, Source Term, and Materials Performance Thrusts in developing unified in-drift models, leading to potential performance enhancement and greater transparency and defensibility.

- Several-orders-of-magnitude enhancement in matrix diffusion within both the UZ and SZ.

- Data indicating trapped colloids at water/air interfaces at an analogue site may imply potential significant reduction of colloid transport at Yucca Mountain (TSPA shows that Pu239 colloids are the second-largest contributor to overall dose, after Tc99). - $\quad$ Potential for one or more orders-of-magnitude increase in $\mathrm{K}_{\mathrm{d}}$ values for several important radionuclides.

\section{References}

1. Office of Science and Technology and International Annual Report FY2005, Department of Energy Report DOE/RW-0581, Department of Energy, Washington DC, USA, 2005.

\section{An International Peer Review of the Yucca Mountain Project Total System} Performance Assessment for the Site Recommendation (TSPA-SR), Joint report by the OECD Nuclear Energy Agency and International Atomic Energy Agency, Office of Economic Organisation and Development, Paris, France, 2002, p. 12.

\section{Post-closure Safety Case for Geological Repositories, Naturè and Purpose, NEA} Report No. 3679, Nuclear Energy Agency, Office of Economic Organisation and Development, Paris, France 2004), pp. 43-44. 


\section{Acknowledgements}

This work is supported by the Director, Office of Civilian Radioactive Waste Management, Office of Science and Technology and International, of the Department of Energy 